\title{
Pengetahuan, Sikap dan Perilaku Masyarakat terhadap Malaria di Wilayah Kerja Puskesmas Hanura
}

\author{
Anindita Shaqiena ${ }^{1}$, Sindi Yulia Mustika ${ }^{1}$ \\ ${ }^{1}$ Mahasiswa Program Studi S1 Pendidikan Dokter Fakultas Kedokteran Universitas Lampung
}

\begin{abstract}
Abstrak
Malaria merupakan penyakit infeksi yang ditularkan oleh gigitan nyamuk Anopheles sp. betina. Lampung merupakan daerah endemis malaria dengan Annual Parasite Incidence (API) yang tinggi. Kabupaten Pesawaran merupakan daerah dengan API tertinggi di Lampung, dengan kasus terbanyak di daerah Hanura. Tingginya angka kejadian malaria di wilayah kerja Puskesmas Hanura dapat disebabkan oleh kurangnya pengetahuan, sikap dan perilaku masyarakat terhadap malaria. Penelitian ini dilakukan dengan studi potong lintang, di wilayah kerja Puskesmas Hanura, khususnya Desa Sukajaya Lempasing. Populasi dalam penelitian ini adalah masyarakat Desa Sukajaya Lempasing dengan sampel sebanyak 35 orang yang terseleksi. Data yang dikumpulkan berupa kuesioner Pengetahuan, sikap dan perilaku. Analisis data dilakukan secara univariat. Hasil penelitian didapatkan, pengetahuan masyarakat tentang malaria sudah baik dilihat dari tingginya persentase masyarakat yang mengetahui tentang malaria dan gejalanya, berikut upaya pencegahan dan pengendaliannya. Masyarakat yang setuju untuk melakukan penghindaran diri terhadap gigitan nyamuk sebanyak $91 \%$, sebanyak $97 \%$ setuju untuk diambil darahnya dan $94 \%$ setuju dalam keterlibatan upaya pemberantasan nyamuk. Simpulan penelitian ini adalah pengetahuan, sikap dan perilaku masyarakat terhadap malaria di Wilayah Kerja Puskesmas Hanura sudah baik.
\end{abstract}

Kata Kunci :Malaria, PSP, Desa Lempasing

\section{Community Knowledge, Attitude, and Practice on Malaria in the Work Area of Hanura Health Center}

\begin{abstract}
Malaria is an infectious disease transmitted by Anopheles sp. female. Lampung is a malaria endemic area with a high Annual Parasite Incidence (API). Pesawaran Regency is the area with the highest API in Lampung, with the most cases in the Hanura area. The high incidence of malaria in the working area of the Hanura Health Center can be caused by a lack of knowledge, attitudes and behavior of the community towards malaria. This research was conducted with a cross-sectional study, in the working area of Hanura Health Center, specifically Sukajaya Lempasing Village. The population in this study is the community of Sukajaya Lempasing Village with a sample of 35 selected people. Data collected in the form of questionnaires Knowledge, attitudes and behavior. Data analysis was performed univariately. The results obtained, community knowledge about malaria is good seen from the high percentage of people who know about malaria and its symptoms, as well as prevention and control efforts. The people who agreed to avoid the mosquito bites were 91\%, 97\% agreed to have blood drawn and $94 \%$ agreed in the involvement of the mosquito eradication effort. The conclusion of this research is that the knowledge, attitudes and behavior of the community towards malaria in the Work Area of the Hanura Health Center are already good.
\end{abstract}

Keywords : Malaria, KAP, Lempasing Village

Korespondensi: Anindita Shaqiena, Prodi Pendidikan Dokter, Fakultas Kedokteran Universitas Lampung, Jl. Ir. Soemantri Brojonegoro No.1, mobile 082122272829, e-mail shaqiena@outlook.com 


\section{Pendahuluan}

Malaria merupakan penyakit infeksi yang disebabkan oleh Plasmodium sp yang ditularkan oleh gigitan nyamuk Anopheles sp betina. Kasus malaria paling sering terjadi pada daerah tropis dan subtropis. Parasit ini hidup dan berkembang biak di dalam sel darah merah manusia. Secara alamiah, penularan malaria terjadi karena interaksi antara agent (Plasmodium sp), hostintermediate (manusia), dan hostdefinitive (Anopheles sp) (World Health Organization, 2010).

Penularan malaria dilakukan oleh nyamuk betina dari Anopheles, sehingga terjadi infeksi pada sel darah merah oleh Plasmodium yang ditularkan melalui gigitan nyamuk Anopheles, transfusi darah, dan suntikan dengan jarum yang sebelumnya telah digunakan oleh penderita malaria. Pada tubuh manusia, parasit membelah diri dan bertambah banyak di dalam hati dan kemudian menginfeksi sel darah merah (Ideham, 2009).

Penyakit malaria memiliki gambaran klinis demam periodik, anemia, dan splenomegali. Keluhan prodormal dapat terjadi sebelum terjadinya demam berupa lesu, sakit kepala, sakit punggung, menggigil, nyeri sendi dan tulang, demam ringan, anoreksia, nyeri perut dan tandatanda lainnya (Satoto, 2018). Keluhan prodormal tersebut sering terjadi pada infeksi $P$. vivax dan $P$. ovale, sedangkan pada infeksi $P$. falciparum dan $P$. malariae keluhan prodormal ini tidak jelas. Gejala khas pada malaria disebut triasmalaria, yang meliputi periode dingin, periode demam, dan periode berkeringat. Periode dingin terjadi selama 15-60 menit.Pasien mulai menggigil dan membungkus diri dengan selimut atau sarung (Fitri, 2017).

Selanjutnya pada periode demam terjadi peningkatan suhu tubuh selama 2-4 jam. Periode terakhir yaitu periode berkeringat dimana penderita berkeringat banyak dan suhu tubuh menurun, serta penderita merasa sehat. Trias malaria lebih sering terjadi pada infeksi $P$. vivax (Harijanto, 2014). Pemeriksaan yang dilakukan untuk mendiagnosis Malaria berupa pemeriksaan mikroskopis dilakukan pada sediaan darah tebal dan tipis untuk mengetahui hasil positif dan negatif Plasmodium sp, dan mengidentifikasi jenis Plasmodium sp (Direktorat Jendral PP \& PL, 2011)

Pada tahun 2017, kasus malaria di dunia mencapai 216 juta kasus. Dari total kasus, didapatkan $90 \%$ terjadi di daerah Afrika. Maka PBB memasukkan malaria bersama AIDS dan tuberkulosis ke dalam SDGs (Sustainable
Development Goals). Targetnya adalah menurunkan mortalitas dan morbiditas malaria lebih dari $90 \%$ pada tahun 2030 (World Health Organization, 2015).

Pemerintah Indonesia juga masih memandang malaria sebagai ancaman terhadap status kesehatan masyarakat terutama pada rakyat yang hidup di daerah terpencil. Hal ini tercermin dengan dikeluarkannya Peraturan Presiden Nomor: 2 tahun 2015 tentang Rencana Pembangunan Jangka Menengah Nasional tahun 2015 - 2019 dimana malaria termasuk penyakit prioritas yang perlu ditanggulangi (Kemenkes RI, 2017).

Lampung merupakan daerah endemis malaria karena banyak ditemukan rawa-rawa, genangan air payau di tepi laut, dan tambaktambak terlantar yang dapat menjadi tempat perkembangbiakan nyamuk Anopheles. Provinsi Lampung memiliki Annual Parasite Incidence (API) atau angka kesakitan malaria di atas rata-rata nasional.API tertinggi di Provinsi Lampung ada di Kabupaten Pesawaran sebesar $(6,36)$, Pesisir Barat $(3,47)$, dan Kota Bandar Lampung $(0,58)$ seperti yang ditampilkan pada gambar 1. Menurut data terbaru pada tahun 2016, API Kabupaten Pesawaran mengalami penurunan menjadi 4.44 per 1000 penduduk (Dinas Kesehatan Kabupaten Pesawaran, 2017).

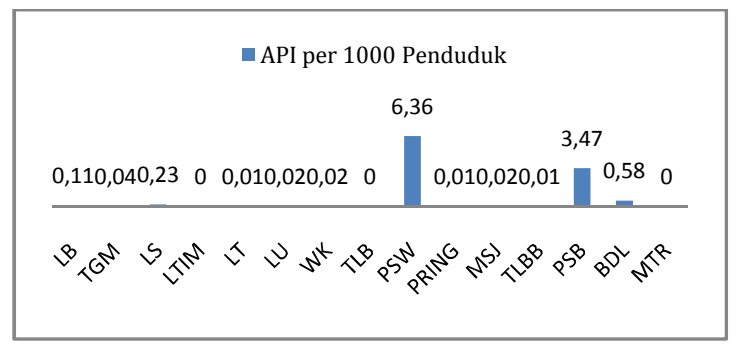

Sumber: Dinas Kesehatan Kabupaten Pesawaran, 2017

Gambar 1. API Per Kabupaten Kota Se-Provinsi Lampung Tahun 2015

Kasus positif malaria terjadi di 4 wilayah yaitu Puskesmas Hanura (1.738 kasus), Puskesmas Padang Cermin (91 kasus), Puskesmas Pedada (82 kasus), dan Puskesmas Gedong Tataan (4 kasus). Tingginya kasus malaria di wilayah tersebut dikarenakan kondisi alam yang mendukung sebagai tempat perindukan nyamuk seperti hutan, laguna, dan tambak terlantar (Dinas Kesehatan Kabupaten Pesawaran, 2017). 


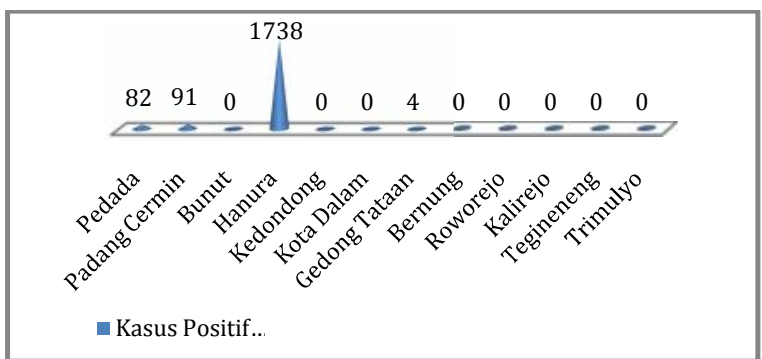

Sumber: Dinas Kesehatan Kabupaten Pesawaran, 2017

Gambar 2. Jumlah Kasus Malaria Berdasarkan Puskesmas di Kabupaten Pesawaran tahun 2016

Pengetahuan tentang vektor malaria, pola perilaku nyamuk (waktu menggigit dan istirahat) dan tempat berkembang biak telah dikaitkan dengan tingkat keparahan malaria. (Killeen, 2014). Sebuah penelitian di Tanzania, dengan mayoritas peserta perempuan, menunjukkan pemahaman yang buruk tentang pola perilaku nyamuk dan tempat berkembang biak di daerah dengan prevalensi malaria yang tinggi. (Mathania, 2016).

Tingginya angka kejadian malaria di wilayah kerja Puskesmas Hanura dapat disebabkan oleh kurangnya pengetahuan, sikap dan perilaku masyarakat terhadap malaria. Maka dari itu, peneliti tetarik untuk meneliti tentang pengetahuan, sikap dan perilaku masyarakat terhadap pencegahan penyakit malaria di wilayah kerja Puskesmas Hanura Kabupaten Pesawaran.

\section{Metode}

Penelitian ini merupakan penelitian deskriptif dengan desain penelitian cross sectional. Penelitian ini dilakukan di Desa Sukajaya Lempasing, Hanura pada bulan Oktober 2019. Sampel adalah masyarakat desa Sukajaya Lempasing. Alat yang digunakan adalah kuesioner PSP dengan prosedur penjelasan penelitian, pengisian informed consent, kemudian pengisian kuesioner. Kriteria sampel adalah warga yang bertempat tinggal di wilayah Sukajaya Lempasing, Hanura dan bersedia untuk menjawab kuesioner yang ada. Sampel yang digunakan dalam penelitian ini sebanyak 35responden dipilih secara purposive sampling. Analisis data dilakukan secara deskriptif dengan menggunakan tabel distribusi frekuensi.

\section{Hasil}

Survei pengetahuan, sikap dan perilaku tentang malaria ini dilakukan pada masyarakat di Desa Sukajaya Lempasing, Hanura dengan responden sebanyak 35 orang yang bersedia di wawancara.

Secara umum pengetahuan masyarakat tentang penyakit malaria sudah cukup baik. Hal ini ditandai dengan tingkat persentase yang cukup tinggi dari masyarakat yang sudah pernah mendengar tentang malaria yaitu sebanyak 35 orang $(100 \%)$, masyarakat yang mengetahui tanda dan gejala malaria sebanyak 35 orang (100\%), serta cara penularan malaria dan cara pencegahan malaria itu sendiri. Hal ini dapat dilihat pada tabel 1 .

Tabel 1. Pengetahuan Masyarakat Tentang Malaria di Desa Lempasing

\begin{tabular}{|c|c|c|c|}
\hline No & Pengetahuan & Frek & $\%$ \\
\hline 1. & $\begin{array}{l}\text { Apakah anda pernah } \\
\text { mendengar tentang malaria? } \\
\text { a. Pernah } \\
\text { b. Tidak Pernah }\end{array}$ & 35 & 100 \\
\hline 2. & $\begin{array}{l}\text { Dibawah ini kelompok } \\
\text { manakah yang dapat } \\
\text { terserang malaria? } \\
\text { a. Anak-Anak } \\
\text { b. Orang dewasa } \\
\text { c. Lansia } \\
\text { d. Semua umur } \\
\text { e. Tidak tahu }\end{array}$ & 29 & 82 \\
\hline 3. & $\begin{array}{l}\text { Apakah anda mengetahui } \\
\text { gejala malaria? } \\
\text { a. Ya } \\
\text { b. Tidak }\end{array}$ & 35 & 100 \\
\hline 4. & $\begin{array}{l}\text { Gejala malaria apa yang anda } \\
\text { ketahui? } \\
\text { a. Demam berkeringat } \\
\text { b. Pingsan } \\
\text { c. Muntah } \\
\text { d. Tidak tahu }\end{array}$ & $\begin{array}{l}30 \\
5\end{array}$ & $\begin{array}{l}85 \\
15\end{array}$ \\
\hline 5. & $\begin{array}{l}\text { Apakah malaria dapat } \\
\text { menular? } \\
\text { a. Ya } \\
\text { b. Tidak } \\
\text { c. Tidak tahu }\end{array}$ & $\begin{array}{c}29 \\
6\end{array}$ & $\begin{array}{l}82 \\
18\end{array}$ \\
\hline 6. & $\begin{array}{l}\text { Bagaimanakah cara } \\
\text { penularan malaria? } \\
\text { a. Lewat lidah } \\
\text { b. Gigitan nyamuk } \\
\text { c. Bersentuhan dengan } \\
\text { penderita malaria } \\
\text { d. Lewat telapak kaki } \\
\text { e. Lainnya }\end{array}$ & $\begin{array}{c}30 \\
2\end{array}$ & $\begin{array}{c}85 \\
6\end{array}$ \\
\hline 7. & $\begin{array}{l}\text { Nyamuk apakah yang dapat } \\
\text { menularkan malaria? } \\
\text { a. Semua jenis nyamuk } \\
\text { b. Nyamuk tetentu } \\
\text { c. Tidak ada nyamuk yang } \\
\text { menularkan } \\
\text { d. Tidak tahu }\end{array}$ & $\begin{array}{c}8 \\
24 \\
3\end{array}$ & $\begin{array}{c}23 \\
68 \\
9\end{array}$ \\
\hline 8. & $\begin{array}{l}\text { Bagaimana cara mengetahui } \\
\text { orang terkena malaria? } \\
\text { a. Pemeriksaan darah } \\
\text { b. Pemeriksaan mata dan } \\
\text { lidah } \\
\text { c. Pemeriksaan denyut nadi } \\
\text { d. Lainnya } \\
\text { e. Tidak tahu }\end{array}$ & $\begin{array}{c}30 \\
1\end{array}$ & $\begin{array}{c}85 \\
3\end{array}$ \\
\hline
\end{tabular}




$\begin{array}{lcc}\text { 9. Bagaimana cara mencegah } & & \\ \text { penularan malaria? } & & \\ \text { a. Memakai kelambu } & 31 & 88 \\ \text { b. Obat gosok anti nyamuk } & 2 & 6 \\ \text { c. Kawat lubang angin } & & \\ \text { d. Menyemprot kamar } & & \\ \text { dengan obat nyamuk } & & \\ \text { e. Lainnya } & 1 & 3 \\ \text { f. Tidak tahu } & 1 & 3\end{array}$

Sikap masyarakat termasuk dalam kategori sudah baik dalam hal penyakit malaria dan pencegahannya. Hal ini terlihat dari tingginya persentase masyarakat yang menyetujui untuk melakukan upaya-upaya pencegahan penularan malaria. Di mana masyarakat setuju untuk melakukan penghindaran diri terhadap gigitan nyamuk sebanyak 32 orang $(91 \%)$, penebaran ikan pemakan jentik sebanyak 24 orang $(68 \%)$, konsumsi obat profilaksis anti malaria sebanyak 20 orang $(57 \%)$, pengambilan darah sebanyak 34 orang (97\%) dan keterlibatan dalam upaya pemberantasan nyamuk sebesar 33 orang (94\%). Hasil kuisoner sikap dapat dilihat pada tabel 2.

Perilaku yang telah dilakukan dalam upaya mendukung pencegahan malaria sudah baik, antara lain kebiasaan sering keluar malam yang hanya ditemukan pada 16 orang responden $(45 \%)$, bersedia rumahnya untuk disemprot sebanyak 34 orang (97\%), namun sebanyak 10 responden $(28 \%)$ masih berusaha mengobati demamnya sendiri tanpa bantuan tenaga medis, sebanyak 31 orang $(88 \%)$ melakukan penghindaran gigitan nyamuk dengan pemakaian kelambu. Sebanyak 4 orang (11\%) sampel memakai obat nyamuk bakar dan pemakaian obat nyamuk semprot sebanyak 0 orang $(0 \%)$. Untuk upaya pencegahan dengan obat profilaksis anti malaria dan pemeriksaan darah malaria diketahui bahwa sebagian besar sampel penelitian belum pernah melakukan hal tersebut. Perilaku masyarakat dalam hal pencegahan malaria masih dianggap kurang karena masih cukup banyak masyarakat yang suka keluar malam walaupun hanya untuk mengobrol dan sebagian besar masyarakat tidak pernah minum obat pencegahan malaria, sehingga dapat menjadi faktor risiko penularan malaria.

Hasil kuisoner prilaku dapat dilihat pada tabel 3.

Tabel 2. Sikap Masyarakat Tentang Malaria di Desa Lempasing

\begin{tabular}{|c|c|c|c|}
\hline No & Sikap & Frek & $\%$ \\
\hline \multirow[t]{4}{*}{1.} & Penyakit malaria berbahaya & & \\
\hline & a. $\quad$ Setuju & 33 & 94 \\
\hline & Tidak setuju & 2 & 6 \\
\hline & Tidak tahu & & \\
\hline
\end{tabular}

\begin{tabular}{|c|c|c|c|}
\hline \multirow[t]{4}{*}{2.} & \multicolumn{3}{|l|}{$\begin{array}{l}\text { Menghindari diri dari gigitan } \\
\text { nyamuk untuk mencegah } \\
\text { penyakit malaria }\end{array}$} \\
\hline & a. $\quad$ Setuju & 32 & 91 \\
\hline & Tidak setuju & 1 & 3 \\
\hline & Tidak tahu & 2 & 6 \\
\hline \multirow[t]{4}{*}{3.} & $\begin{array}{llr}\text { Menebar } & \text { ikan pemakan jentik } \\
\text { untuk upaya } & \text { pencegahan } \\
\text { malaria } & & \\
\end{array}$ & & \\
\hline & a. $\quad$ Setuju & 24 & 68 \\
\hline & Tidak setuju & 7 & 20 \\
\hline & Tidak tahu & 4 & 12 \\
\hline \multirow[t]{4}{*}{4.} & $\begin{array}{lrr}\text { Memakan } & \text { obat } & \text { untuk } \\
\text { mencegah } & \text { malaria } & \text { meskipan } \\
\text { tidak sakit } & & \end{array}$ & & \\
\hline & a. $\quad$ Setuju & 20 & 57 \\
\hline & Tidak setuju & 15 & 43 \\
\hline & c. Tidak tahu & & \\
\hline \multirow[t]{4}{*}{5.} & $\begin{array}{l}\text { Penderita malaria diambil } \\
\text { darahnya untuk diperiksa }\end{array}$ & & \\
\hline & a. $\quad$ Setuju & 34 & 97 \\
\hline & Tidak setuju & & \\
\hline & c. Tidak tahu & 1 & 3 \\
\hline \multirow[t]{4}{*}{6.} & $\begin{array}{l}\text { Bersedia diambil } \\
\text { meskipun tidak sakit }\end{array}$ & & \\
\hline & a. $\quad$ Setuju & 28 & 80 \\
\hline & Tidak setuju & 7 & 20 \\
\hline & c. $\quad$ Tidak tahu & & \\
\hline \multirow[t]{4}{*}{7.} & $\begin{array}{l}\text { Masyarakat harus dilibatkan } \\
\text { dalam upaya pemberantasan } \\
\text { malaria }\end{array}$ & & \\
\hline & a. $\quad$ Setuju & 33 & 94 \\
\hline & Tidak setuju & 1 & 3 \\
\hline & Tidak tahu & 1 & 3 \\
\hline
\end{tabular}

Tabel 3. Perilaku Masyarakat Tentang Malaria di Desa Lempasing

\begin{tabular}{|c|c|c|c|}
\hline No. & Perilaku & Frek & $\%$ \\
\hline \multirow[t]{4}{*}{1.} & 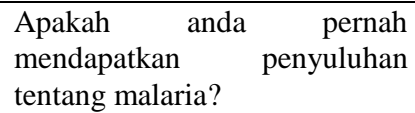 & & \\
\hline & a. Pernah & 29 & 83 \\
\hline & Tidak pernah & 5 & 14 \\
\hline & Tidak tahu & 1 & 3 \\
\hline \multirow[t]{6}{*}{2.} & $\begin{array}{l}\text { Apa yang anda lakukan jika } \\
\text { mengalami demam? }\end{array}$ & & \\
\hline & a. $\quad$ Diobati sendiri & 10 & 69 \\
\hline & Lapor Puskesmas & 24 & 28 \\
\hline & Ke Dukun & & \\
\hline & $\begin{array}{l}\text { d. Dibiarkan sembuh } \\
\text { sendiri }\end{array}$ & 1 & 3 \\
\hline & e. Lainnya & & \\
\hline \multirow[t]{5}{*}{3.} & $\begin{array}{l}\text { Apaah anda sering keluar } \\
\text { malam? }\end{array}$ & & \\
\hline & a. $\quad$ Ya & 16 & 45 \\
\hline & Terkadang & 9 & 26 \\
\hline & Pernah & 2 & 6 \\
\hline & Tidak & 8 & 23 \\
\hline \multirow[t]{7}{*}{4.} & Apa kegiatan yang anda & & \\
\hline & lakukan jika keluar malam? & & \\
\hline & a. Menjaga kebun & & \\
\hline & Ronda & & \\
\hline & Mengobrol & 9 & 26 \\
\hline & $\mathrm{BAB}$ & 1 & 3 \\
\hline & Lainnya & 25 & 71 \\
\hline
\end{tabular}




\begin{tabular}{|c|c|c|c|}
\hline 5. & $\begin{array}{l}\text { Apa yang anda lakukan untuk } \\
\text { menghindari gigitan nyamuk? }\end{array}$ & & \\
\hline & a. $\quad$ Memakai kelambu & 31 & 88 \\
\hline & Memakai obat nyamuk & 4 & 12 \\
\hline & Menyemprot obat & & \\
\hline & nyamuk & & \\
\hline & Lainnya & & \\
\hline 6. & $\begin{array}{l}\text { Apakah anda pernah diambil darah } \\
\text { untuk pemeriksaan malaria? }\end{array}$ & & \\
\hline & a. $\quad$ Pernah & 31 & 88 \\
\hline & Tidak Pernah & 4 & 12 \\
\hline & Tidak tahu & & \\
\hline 7. & $\begin{array}{l}\text { Apakah anda pernah minum obat } \\
\text { pencegah malaria? }\end{array}$ & & \\
\hline & a. $\quad$ Pernah & 15 & 43 \\
\hline & Tidak Pernah & 20 & 57 \\
\hline 8. & $\begin{array}{l}\text { Apakah anda bersedia rumah anda } \\
\text { disemprot untuk memberantas } \\
\text { nyamuk? }\end{array}$ & & \\
\hline & a. $\quad$ Ya & 34 & 97 \\
\hline & b. $\quad$ Tidak & 1 & 3 \\
\hline
\end{tabular}

\section{Pembahasan}

Pengetahuan masyarakat di desa Sukahaya Lempasing, Hanura tentang penyakit malaria sudah cukup baik. Hal ini ditandai dengan persentase yang sudah mengetahui tentang malaria, gejala-gejalanya, cara penularannya, dan berbagai upaya pencegahannya. Sikap masyarakat termasuk dalam kategori sudah baik, ditandai oleh adanya persentase masyarakat yang menyetujui untuk melakukan upaya-upaya pencegahan malaria. Perilaku yang telah dilakukan masyarakat dalam upaya mendukung pencegahan malaria sudah baik.

Pengetahuan terdiri dari tahu, memahami, aplikasi, analisis, sintesis, dan evaluasi. ${ }^{\mathrm{x}}$ Mengacu pada pengetahuan yang disebutkan tersebut, maka dapat dinyatakan bahwa masyarakat desa Lempasing merupakan masyarakat dengan tingkat pengetahuan yang baik. Pengetahuan yang baik akan mendukung adanya penyikapan positif terhadap kejadian malaria yang baik akan melakukan respon terhadap kejadian malaria secara positif. Respon yang positif akan mendorong untuk melakukan upaya-upaya pencegahan agar malaria tidak membahayakan dirinya dan orang-orang di sekitarnya.

Sikap merupakan respon terhadap sesuatu dengan tingkatan menerima, merespon, menghargai dan bertanggungjawab. Berdasarkan hasil dengan nilai persentase yang cukup tinggi tersebut, maka dapat disimpulkan bahwa masyarakat Desa Sukajaya Lempasing memiliki sikap yang baik dalam upaya pencegahan dan penyikapan terhadap malaria.
Perilaku, merupakan tindakan yang terdiri dari berbagai aspek, yakni persepsi, mengenal, dan memilih berbagai objek sehubungan dengan tindakan yang akan diambil dalam usaha pencegahan dan pengendalian vector malaria. Dari perilaku yang telah dilakukan oleh masyarakat Desa Sukajaya Lempasing, beberapa usaha untuk menghindari kontak terhadap kejadian malaria telah dilakukan.

Simpulan penelitian ini adalah pengetahuan, sikap dan perilaku masyarakat terhadap malaria di Wilayah Kerja Puskesmas Hanura sudah baik.

\section{Daftar Pustaka}

Dinas Kesehatan Kabupaten Pesawaran. (2017). Profil kesehatan Kabupaten Pesawaran. Pesawaran : Dinas Kesehatan Kabupaten Pesawaran

Direktorat Jendral PP \& PL. (2011). Pedoman Teknis Pemeriksaan Parasit Malaria. Jakarta: Kemenkes RI

Fitri LE. (2017). Imunologi Malaria: Misteri Interaksi Inang \& Parasit. Malang: UB Press

Harijanto PN. (2014). Malaria. Dalam: Sudoyo AW, Setiati S, Alwi I, Simadibrata M, SetiyohadiB, Syam AF. Buku Ajar Ilmu Penyakit Dalam. Jilid I, Edisi ke VI. Jakarta: InternaPublishing.

Ideham B \& Dachlan YP. (2009). Penuntun Praktis Parasitologi Kedokteran. Surabaya: Airlangga University Press.

Kementerian Kesehatan RI. (2017). Buku saku penatalaksanaan kasus malaria. Jakarta : Kementerian Kesehatan RI

Killeen GF. (2014). Characterizing, controlling and eliminating residual malaria transmission. Malar J. 13: 30

Mathania MM, Kimera SI, Silayo RS. (2016). Knowledge and awareness of malaria and mosquito biting behavior in selected sites within Morogoro and Dodoma regions Tanzania. Malar J. Biomed Central. 15: 287

Satoto TB. (2018). Pedoman Diagnostik Mikroskopis Malaria. Yogyakarta: Gadjah Mada University Press

World Health Organization. (2010). Malaria. WHO technical report series no 936.

World Health Organization (WHO). (2015). Global technical strategy for malaria 2016-2030. Geneva : WHO 